\title{
El movimiento de la existencia: posibilidades y límites de la descripción fenomenológica de la corporeidad
}

\section{The movement of existence: possibilities and limits of the phenomenological description of embodiment}

\author{
César Augusto Delgado Lombana1.
}

\section{Resumen:}

En el presente texto, se pretende evidenciar los alcances de la propuesta de una fenomenología de la percepción desde Maurice Merleau Ponty. En el artículo se desarrollan dos argumentos: el objetivo de Merleau-Ponty quien se opone a las teorías psicologistas que han reducido la percepción a la sensación pura, es decir, a la aprehensión de datos sensitivos aislados. Por el contrario, deseamos evidenciar que Merleau-Ponty comprende la percepción como la interpretación de un horizonte de significación (perspectiva) que permite la correlación entre sujeto y objeto. En sentido estricto, percibir es la posibilidad de comprender que el objeto se da en ámbitos de significación que permiten la constitución entre sujeto y objeto. Esta tesis tendrá por consecuencia más próxima que la escisión sujeto objeto se supere y se vea la doble faz de la percepción: la perspectiva (estructura objeto-horizonte), la cual me permite experienciar objetos no como meros datos aislados, sino como horizonte, es decir, como ámbitos de significación. En segundo lugar, será necesario abordar las críticas de Merleau-Ponty a las teorías sobre el cuerpo que, en su aspecto más radical, han conducido a la cosificación del mismo, es decir, a la reducción de la corporalidad a una cosa más entre las cosas.

\section{Palabras clave:}

Ser del mundo, percepción, fenomenología, corporalidad.

\section{Summary:}

This paper presents phenomenology from the point of view of Maurice Merleau Ponty. Two arguments are developed: Merleau-Ponty's aim is opposed to the psychologist theories that reduce perception to pure sensation, that is to say, to the apprehension of isolated sensual information. In contrast, we want to demonstrate that Merleau-Ponty understands perception as the interpretation of an horizon of meanings and perspectives that leads to correlations between subject and object. In strict sense, to perceive is to understand that the object shows itself in areas of meaning that leads to its constitution between subject and object. This thesis will have as immediate consequence that the gap between subject and object disappears. Besides that, the double aspect of perception becomes evident. Perspective (structure, object and horizon) allows one to experience objects not as mere isolated information, but as a horizon, that is to say, as fields of meaning. Secondly, it will be necessary to approach Merleau-Ponty's critiques to the theories about the body whose more radical position has led to its own objectification, that is to say, to the reduction of embodiment to just one thing.

Key words:

Being from the world, perception, phenomenology, embodiment.

Artículo recibido el 21 de abril de 2009 y aprobado el 30 de abril 2010.

1 Licenciado en Ciencias Sociales. Universidad Pedagógica Nacional. Candidato a Master en Filosofía, Pontificia Universidad Javeriana. Profesor Universidad Pedagógica Nacional y Universidad Los Libertadores. Hermeneia18@yahoo.es 
La existencia no es objeto posible de saber, del conocimiento, sino algo que sólo puede convocarse, a lo que sólo puede apelarse. (...) La existencia es, en suma, ese núcleo en el hombre que cabe delimitar como su humanidad, lo que el hombre puede ser y está llamado a ser y que, sin embargo, nunca es cognoscible y nunca clausurable. Es la incondicionalidad del hombre, como una expresión adicional de la paradójica contradicción que late en el núcleo.

Jan Patocka, 2000, p. 69

La fenomenología es concebida por Husserl como un nuevo método ${ }^{2}$, que tiene como tarea primordial alcanzar el eidos de aquello que se escapa a la ciencia y a la filosofía dogmática. Pretende comprender aquello que no es objeto de posible verificación, porque antecede a toda posibilidad tética. La fenomenología es un método descriptivo que desea destruir la objetividad vacía y la razón desolada, con el fin de evidenciar que las preguntas fundamentales de la existencia se responden desde ella misma. La fenomenología es la defensa y posibilidad más próxima de la subjetividad encarnada fundada en la intersubjetividad operante, a su vez, que es el vehículo para pensar una ontología del mundo de la vida. Pero, además de ser un ámbito de posibilidad para describir ¿cómo es que se da el mundo a la conciencia?, también la fenomenología es concebida como un método crítico que pretende desvelar lo que se encuentra oculto en las pretensiones de objetivación: el hombre y su correlación con el mundo de la vida.

Es por este motivo que Husserl, desde sus primeras obras, siempre se propuso abordar problemas fundamentales como: la relación entre cuerpo y percepción, la escisión sujeto-objeto, la conciencia y la intencionalidad, el mundo, el sujeto y la intersubjetividad. De este programa, propuesto por

2 Así lo declara Husserl en el artículo Fenomenología de la Enciclopedia Británica. "Fenomenología designa un nuevo método descriptivo que hizo su aparición en la filosofía a principios de siglo y una ciencia apriórica que se desprende de él y está destinada a suministrar el órgano para una filosofía rigorosamente científica y a posibilitar, en un desarrollo consecuente, una reforma metódica de todas las ciencias" (Husserl, 1998, p. 35). Empero, este sentido de la fenomenología cambiará de forma radical en la obra cumbre de Husserl Krisis, porque en ésta se deja ver un Husserl menos preocupado por la fundamentación de una filosofía rigurosa, y más bien dirigido hacia el asunto del mundo de la vida.
Husserl para la fenomenología, surgió un amplio ámbito de indagación que será conocido como movimiento fenomenológico que Ricoeur interpretara como: "la historia de las herejías husserlianas". No es fortuito, por tanto, que Merleau-Ponty afirmara que la fenomenología "nos lo dio todo". Muestra de ello es el programa que el filósofo francés desarrolla en su obra central Fenomenología de la percepción, en la cual, valiéndose del método fenomenológico quiere hacer frente a dos preguntas de gran alcance: $¿$ es el sujeto un empobrecido acto de conciencia, sin cuerpo, sin espacio, sin tiempo?, o ¿acaso el sujeto sólo puede ser explicado como una cosa más entre las cosas del mundo?

Con el objetivo de responder estas preguntas, Merleau-Ponty debe retomar uno de los ejes centrales de la empresa fenomenológica: la corporalidad y su correlación con el mundo de la vida. Empero, el filósofo francés se verá obligado a superar los límites que la propia descripción fenomenológica pensada por Husserl le impone y, para hacerlo, se le hace imperativo alcanzar un nuevo ámbito de interpretación de la teoría del cuerpo y la percepción que, impulsada por Husserl, le servirá de piedra angular para fundamentar su crítica al psicologismo y a la ciencia positiva que pretenden hacer del cuerpo una cosa entre las cosas.

De esta forma, el objetivo del presente texto es mostrar los alcances de una fenomenología de la percepción. Para ello nos proponemos desarrollar dos argumentos centrales: el objetivo de MerleauPonty es oponerse a las teorías psicologistas que han reducido la percepción a la sensación pura, es decir, a la aprehensión de datos sensitivos aislados. Por el contrario, deseamos evidenciar que Merleau-Ponty comprende la percepción como la interpretación de un horizonte de significación (perspectiva) que permite la correlación entre sujeto y objeto. En sentido estricto, percibir es la posibilidad de comprender que el objeto se me da en ámbitos de significación que permiten la constitución entre sujeto y objeto. Esta tesis tendrá por consecuencia más próxima que la escisión sujeto objeto se supere y se vea la doble faz de la percepción: la perspectiva (estructura objeto-horizonte) 
me permite experienciar objetos no como meros datos aislados, sino como horizonte, es decir, como ámbitos de significación.

En segundo lugar, será necesario abordar las críticas de Merleau-Ponty a las teorías sobre el cuerpo que en su aspecto más radical han conducido a la cosificación del mismo, es decir, a la reducción de la corporalidad a una cosa más entre las cosas. Deseamos sostener, entonces, que la fenomenología de la percepción tendrá por resultado evidenciar que experienciar mundo del ser-del-mundo es posible gracias a la corporalidad que se niega a ser objetivada. El texto se divide entres partes:

- Desde Husserl y contra Husserl: apuntes críticos de Merleau-Ponty frente al método fenomenológico.

- Horizonte, perspectiva y sentido.

- Críticas al mecanicismo y a la fisiología.

\section{Desde Husserl y contra Husserl: apuntes críticos de Merleau-Ponty frente al método fenomenológico}

Seguir el pensamiento de Husserl no es sencillo, más aún, cuando en su obra se trata de indagar por su teoría de la percepción y del cuerpo, la cual experimentó gran variedad de modificaciones desde sus libros: las Investigaciones lógicas (1900) hasta la Krisis (1937). Empero, -y sin el ánimo de incurrir en reducciones simplistas-, es posible asegurar que sus teorías sobre la "esfera de lo mío propio"3 y la "donación de esbozos" desarrollada a lo largo

3 No sobra recordar que Husserl aborda el asunto de la "esfera de lo mío propio" en las Meditaciones cartesianas, y específic amente en la Quinta meditación (donde la esfera trascendental del ser se revela como intersubjetividad monadológica), y que podemos considerar como punto culminante y central de la exposición efectuada por Husserl, la cual intenta dar cuenta de la relación entre la subjetividad operante (ego constituyente) y la alteridad constituida. De entrada, la aporía de la intersubjetividad se encuentra determinada por la imposibilidad de interpretar el estatuto de la alteridad sin antes pasar por la preponderancia que el ego operante tiene sobre el otro, es decir, la imposibilidad de aceptar la objetividad de la intersubjetividad si no se presume la certeza del sujeto trascendental. En otras palabras, es imposible para Husserl evidenciar el carácter constitutivo del ego, sin sacrificar antes la originalidad de la alteridad que al parecer queda reducida a la mera extensión del sujeto trascendental (Husserl, 1986, pp. 149-217). de su obra, nos permite establecer por lo menos un punto de partida esencial: contra el psicologismo y la filosofía positiva, la fenomenología pretende sostener que la percepción debe ser interpretada como “donación de esbozos", lo cual nos permite entender que la percepción es distinta de la sensación y la intelección. Pero enseguida es necesario preguntar: ¿en qué consiste la "donación de esbozos"? La "donación de esbozos" le permite a Husserl aprehender que la percepción no es la mera recepción de sensaciones aisladas; por el contrario, la percepción debe ser vista como donación. La 'donación’ es la captación de la unidad de lo percibido que finalmente no es esclava de las sensaciones, sino que se vale de ellas para manifestarse.

En efecto, no percibo de forma aislada datos sueltos sobre el libro que tengo enfrente de mí en estos momentos, percibo cualidades de un objeto que se me da a la conciencia como una unidad inteligible cuando relaciono sus partes con el todo (reflexión), esto por supuesto mediado por la perspectiva desde la que se me da el entorno cósico. De esta forma, confirmo que el objeto sólo puede ser percibido como objeto de vivencia, es decir, dado a la conciencia que es siempre conciencia de algo, cogitatio-cogitatum. Con la teoría de la donación de esbozos Husserl también busca radicalizar que entre sujeto y objeto existe un correlato que obliga a pensar la relación entre noema y noesis: entre la conciencia, acto intencional, el cogitatio (noesis) y el objeto intencional, el cogitatum (noema).

Por un lado, tenemos, pues, que distinguir las partes y los elementos que encontramos mediante un análisis de los ingredientes de la vivencia, en que tratamos a ésta como cualquier otro objeto, preguntado por sus trozos o por los elementos independientes que la integran como ingredientes. Mas, por otro lado, es la vivencia intencional conciencia de algo, y lo es por su esencia, por ejemplo, en cuanto recuerdo, en cuanto juicio, en cuento volición, y así podemos preguntar qué es lo que hay que decir esencialmente de este "de algo" (Husserl, 1949, § 88. 213). 
Enseguida, Husserl también afirma que a pesar del correlato entre sujeto y objeto la teoría de la donación de esbozos tendrá que hacer manifiesto que sujeto y objeto no pueden reducirse el uno al otro. Lo que se demuestra es que cada uno se afirma como alteridad, que permite al sujeto interpretarse como principio operatorio del acto de constitución que será llevado a cabo a través de de la reducción trascendental. En esta medida Husserl sigue influido por Descartes y Kant, en tanto la fenomenología no puede presidir de la preponderancia de cogito. Empero, se separa de Descartes cuando pone como condición sine qua non de la conciencia el cogitatum. Es decir, a pesar de someter la totalidad de la objetividad del mundo a la epojé, ésta encuentra su límite en la vivencia sin la cual el cogito no es nada. Ahora bien, ¿cuál es el papel del cuerpo en la teoría de la percepción? Husserl lo explicita de forma directa en el siguiente enunciado:

Dirijamos la mirada al cuerpo (leib) y a la espacio-temporalidad que lo circunda. Cada Yo, se encuentra a sí mismo como teniendo un cuerpo orgánico, que no es, por su parte, ningún Yo, sino una cosa espacio-temporal alrededor de la cual se agrupa un entorno cósico que se extiende sin límite (Husserl, 1994: § 2. 48).

En este aspecto Husserl pretende diferenciar entre el cuerpo biológico (korpe), evidencia inmediata de la actitud natural, y el cuerpo vivido, la corporeidad (leib). Husserl no desconoce la eficiencia del cuerpo objetivo, el cual se da como evidencia inmediata y alrededor del cual los objetos se organizan y se prestan a la percepción. Sin embargo, del korpe (cuerpo biológico), la fenomenología hará notar que es la concepción del cuerpo más empobrecida, reducido a una cosa, restringida por las objetividades de la ciencia. Pero el cuerpo no es sólo eso, no es sólo una cosa, la fenomenología dirige su atención al cuerpo vivido que es el vínculo que permite el encuentro entre sujeto y mundo. Es así como Husserl concibe el cuerpo como "punto cero del sistema de coordenadas desde el que piensa, ordena y conoce todas las cosas del mundo, tanto las ya conocidas como las que no lo son" (Husserl, 1994: §5. 52).

Pero, ¿cuál es el límite de la teoría husserliana de la percepción? La respuesta se encuentra de inmediato si se analiza la teoría de la inmanencia de la conciencia, la cual nos permite esbozar los límites del método fenomenológico en Husserl. El padre de la fenomenología, a pesar de descubrir el error del psicologismo, no puede superar la referencia a la conciencia como un dominio cerrado. La conciencia interpreta sensaciones y esto posibilita la aparición de los objetos. De esto, se infiere que la conciencia tiene un peso exacerbado en la propuesta de Husserl, pues la conciencia tiene la tarea de interpretar la sensación para posibilitar la percepción; sin los datos y vigilancia de la conciencia la sensación es ininteligible. Es necesario que la conciencia se doble y permita la reflexión como modo de acceso al objeto, la reflexión es mediadora de las sensaciones oscuras de la sensibilidad.

Heidegger crítica en Ser y tiempo este presupuesto de la fenomenología trascendental y se separa del concepto de sujeto trascendental para hablar del Dasein ${ }^{4}$. Es quizás este el camino que le permita a Merleau-Ponty abandonar el presupuesto de la conciencia reflexiva:

Husserl atribuyó a la reflexión un poder, que ella no posee. En efecto, podemos, por ejemplo, estar concientes de que recordamos, percibimos, pero el percibir o el recordar mismo no se ofrecen allí, en la reflexión, como un nuevo objeto visible y todo lo que hace ésta al respecto no es sino analizar lo percibido en cuanto tal e inferir de él características que le deberían corresponder a la noesis

4 Así lo ve Gadamer, cuando muestra los límites del análisis husserliano y las críticas que Heidegger hace a partir de sus obras tempranas, al método fenomenológico. "Sin embargo, Heidegger no se ve alcanzado por las mismas implicaciones epistemológicas según las cuales, La vuelta a la vida (Dilthey) al igual que la reducción trascendental (la autorreflexión radical de Husserl), tienen su fundamento metódico en la forma como las vivencias están dadas por sí mismas. Esto es más bien el objeto de su crítica. Bajo e término clave de una hermenéutica de la facticidad, Heidegger se opone a la fenomenología eidética de Husserl, y a la distinción entre hecho y esencia sobre la que reposa, una exigencia paradójica. La facticidad del estar ahí, la existencia, que no es susceptible ni de fundamento ni de deducción". (Gadamer, 1993, p. 313). 
perceptiva por ser correlato de aquel. La reflexión es esencialmente noemática. La posibilidad de conjeturar indirectamente, a través del noema, las caracterizaciones de la conciencia, ha hecho creer a Husserl que la reflexión es un conocimiento intuitivo de objetos (Rosales, 2000, p. 108).

Es frente a este presupuesto de la fenomenología que Merleau-Ponty toma distancia de Husserl, al no hacérsele claro el peso que la conciencia trascendental tiene como garante de la percepción. Frente a este presupuesto sostiene que la percepción es de entrada interpretación de sentido y, a su vez, logra construir con mayor exactitud los esbozos de una fenomenología genética. Es decir, que no se queda atrapado en el marco de una fenomenología estática que pretende explicitar el darse de los objetos a la conciencia. El objetivo de Merleau-Ponty es más ambicioso cuando pretende indagar por el cuerpo como medio del ser-del- mundo.

\section{Horizonte, perspectiva y sentido}

Pero de una vez por todas dirijamos nuestra mirada a la propuesta de Merleau-Ponty y desvelemos en qué consiste su análisis de la percepción. En la Fenomenología de la percepción, específicamente en la primera parte titulada El cuerpo (Merleau-Ponty, 1984, pp.87-107), el preámbulo al primer apartado se encuentra dedicado a ofrecer una descripción de su teoría de la percepción que tiene como eje central la mirada y su relación con la perspectiva de percepción. $\mathrm{Su}$ análisis comienza con un ejemplo clarificador, a propósito de la perspectiva:

Nuestra percepción remata en unos objetos, y el objeto, una vez constituido, se revela como razón de todas las experiencias que del mismo hemos tenido o podríamos tener. Por ejemplo, veo la casa vecina desde cierto ángulo, otro individuo desde la orilla del Sena, la vería de forma diferente, de una tercera forma desde el interior y toda vía de una cuarta diferente desde un avión; la casa de sí no es ninguna de estas apariciones, es, como decía Leibniz el geometral de estas perspectivas y de todas las perspectivas posibles, eso es, el término sin perspectiva desde el que pueden derivarse todas, es la casa vista desde ninguna parte (Merleau-Ponty, 1984, p. 87).

Lo primera que debe decirse es que MerleauPonty amarra de nuevo el análisis de la percepción a la perspectiva. Pero ¿qué es la perspectiva? En una primera tentativa, podríamos afirmar, que la perspectiva es el horizonte en el cual se me da el objeto, que tiene por presupuesto mi ubicación espacial y temporal. Ejemplifiquemos. Me encuentro en mi habitación, pero de ésta no tengo más que una perspectiva posible, la que se da de inmediato a mi mirada, el ordenador y los libros que se encuentran a su alrededor. Pero supongamos que cabe la posibilidad de un segundo observador que se ubica detrás de mí, su perspectiva es mi espalda y la totalidad de la pared sobre la que se encuentra mi escritorio. Visto de cerca, la perspectiva entraña dos problemáticas iniciales: ¿cómo la mirada puede mantenerse siempre en apertura para no cerrase sobre sí misma, sobre su propia perspectiva? Y si lo único que tenemos del objeto es una perspectiva ¿cómo poder apropiarnos de la totalidad del objeto?

Con respecto a la primera pregunta, cabe advertir que una perspectiva a la vez que me muestra una cara del objeto, también me oculta otra faceta del mismo, aquella que no se da de inmediato a mi mirada. De esta forma, podemos señalar que toda perspectiva ganada es también una fuga de horizonte. Merleau-Ponty lo tiene claro cuando descubre que la perspectiva permite la desvelación pero de nuevo el ocultamiento. Avancemos. ¿Cómo superar la fuga de la perspectiva? La solución se encuentra dada desde un principio. La perspectiva jamás está cerrada sobre sí misma, percibir un objeto no es captar sensaciones vacías de un ente desolado, mirar es la posibilidad de alcanzar un horizonte de significación del que surge un contexto que me clarifica el sentido del objeto percibido.

Ejemplifiquemos, volvamos a mi habitación. He dicho que mi horizonte son los libros y el ordenador, mi mirada siempre está puesta sobre la pantalla, en donde aparecen las oraciones que escribo, pero de antemano experiencio que mi visión se encuentra abierta a la copresencia, a eso otro que configura 
mi horizonte de significación: el escritorio sobre el cual se encuentra el ordenador, los libros, y la silla sobre la que estoy sentado. Estos objetos son los que constituyen mi perspectiva, la cual no me es dada como meros datos inconexos, pues a través de ellos he podido reconocer que me encuentro en $\mathrm{mi}$ habitación, que junto a mi están los objetos, que no me poso frente a ellos como un observador neutral y frío. En realidad, es preciso afirmar que habito los objetos que se me dan en el horizonte; es verdad, los objetos toman para mí un sentido porque me encuentro experienciándolos. El ordenador no es simplemente una máquina negra el ordenador me permite escribir el texto que el día jueves leeré enfrente de los asistentes al seminario, el libro me permite clarificar mis ideas; la silla y el escritorio, posar mi corporalidad para poder escribir.

El horizonte es, pues, lo que asegura la identidad del objeto en el curso de la exploración, es el correlato del poder próximo que guarda mi mirada sobre los objetos que acaba de recorrer y que ya tiene sobre los nuevos detalles que va a describir [...] La estructura objeto [de] horizontes, eso es, la perspectiva, no me estorba cuando quiero ver al objeto: si bien es el medio [por el cual] los objetos disponen para disimularse, también lo es para poder revelarse. Ver es entrar en un universo de seres que se muestran, y no se mostrarían si no pudiesen ocultarse unos detrás de los demás o detrás de mí. En otros términos, mirar un objeto, es venir a habitarlo, y desde ahí captar las cosas según la cara que al mismo presenten (Merleau-Ponty, 1984, p. 88).

Pero aún falta clarificar la segunda problemática: si lo único que tenemos del objeto es una perspectiva, ¿cómo poder apropiarnos de la totalidad del objeto? La descripción fenomenológica tanto de Husserl como de Merleau-Ponty contempla la posibilidad de cambiar nuestra perspectiva. Podemos dar la vuelta, puedo mirar el objeto desde otro ángulo, mi horizonte se modifica y me permite captar la faz desconocida del objeto. Sin embargo, no podemos contentarnos con esto; si hemos afirmado que el horizonte se constituye en sus relaciones espaciales y temporales, esto indica que mi horizonte también se constituye de aquello que no pudo ver, pero que seguramente se proyecta sobre la relación de un objeto con otro.

Merleau-Ponty lo ejemplifica con el caso de la lámpara. La lámpara se encuentra sobre la mesa, de ella solo captó su frente, pero la chimenea tiene de la lámpara la espalda que yo supongo está ahí. Merleau-Ponty muestra cómo "cada objeto es el espejo de todos los demás" (Merleau-Ponty, 1984, p.88). Cada horizonte es un sistema interrelacionado en donde se fusionan infinidad de perspectivas que puedo alcanzar a través de mi mirada que permite el habitar de los objetos. Pero cuidado, nuestra mirada nunca tiene a su disposición el objeto en su totalidad, sólo dispone de horizontes. Empero, este punto ciego de la perspectiva debe ser interpretado como un límite positivo. En efecto, esta imposibilidad de disponer del todo nos hace conscientes de nuestra finitud: nuestra mirada es finita porque nuestro conocimiento, por fundarse en nuestras perspectivas, hunde sus raíces en la temporalidad, ya que nunca alcanzamos la totalidad de las cosas, y nunca podemos reducir el mundo a la conciencia omnipotente. Por el contrario, la conciencia se ve rebasada por la apertura de nuestros infinitos horizontes que son campos extensos de posibilidades. Esta última afirmación puede ser interpretada como un golpe directo contra la ciencia moderna y su pretensión de encarcelar el sentido del mundo en "sistemas téticos". La ciencia es una perspectiva más, la ciencia se encuentra con infinidad de horizontes que le recuerdan que la finitud se encuentra instalada en el corazón de nuestro mirar.

Puedo, pues, ver un objeto en cuanto que los objetos forman un sistema o un mundo y que cada uno de ellos dispone de los demás, que está a su alrededor, como espectadores de sus aspectos ocultos y garantía de su permanencia [...] Pero, insistamos, mi mirada humana nunca pro-pone del objeto más que una cara, incluso si, por medio de los horizontes, apunta a todas las demás (Merleau-Ponty, 1984, pp. 88-89).

Ahora se nos ha hecho claro que Merleau-Ponty entiende la percepción como comprensión de sen- 
tido, porque percibir es descubrir un horizonte de significación que determina la constitución del sujeto y del objeto. Cuando percibimos objetos no lo hacemos por fuera del horizonte de donde nace; por el contrario, lo captamos en su infinidad de relaciones temporales y espaciales. Ejemplifiquemos. Contra el psicologismo que hace de la percepción un ejercicio mecánico de capturar sensaciones inconexas y aisladas, Merleau-Ponty quiere explicar que percibir el color rojo de un objeto es a su vez comprender que se trata de la cubierta del pocillo que se encuentra sobre mi mesa. Lo percibido es el color rojo que constituye al pocillo, el sistema de interrelaciones del pocillo y de mi mirada que recubre el horizonte de lo dado. En efecto, no percibimos sensaciones aisladas que pretenden satisfacer la idea abstracta de rojo que contiene la conciencia: "es este éxtasis de la experiencia lo que hace que toda percepción sea percepción de algo de una cosa" (Merleau-Ponty, 1984, p. 90).

Pero aún podemos llevar al máximo la tesis de Merleau-Ponty y mostrar hasta dónde la relación sujeto-objeto parece haber trasgredido los límites que la metafísica había impuesto. Si lo que la percepción permite es la toma de un horizonte de significación, esto indica que finalmente el sentido emana de la relación del mirar que es un habitar. Estoy en el objeto y él en mí. La correlación propuesta por Husserl gana la potencia necesaria para evidenciar los múltiples planos de constitución que surgen entre el sujeto y el objeto. Es gracias a mi mirada en perspectiva que habito el mundo, que el mundo deviene mundo para un cuerpo que se instala en la infinitud de las perspectivas. Así lo describe el filósofo francés en Sentido y sin sentido:

Me doy cuenta que la cosa, después de todo, necesita de mí para existir. Cuando descubro un paisaje hasta entonces escondido por una colina, sólo en este momento llega a ser plenamente paisaje, y no puede concebirse lo que sería una cosa sin la inminencia o la posibilidad de mi mirada sobre ella. Este mundo que tenía toda la apariencia de existir sin mí, de rodearme y de excederme, existe gracias a mí. Yo soy, pues, una conciencia, una presencia inmediata en el mundo, y no hay nada que pueda pretender existir sin quedar cogido de alguna manera en el tejido de mi experiencia. Yo no soy esta persona, este rostro, este ser finito, sino un puro testigo, sin lugar y sin edad, que puede igualar en potencia a la infinidad del mundo (Merleau-Ponty, 2000, p. 61).

La mirada no es la mera captación de colores, tamaños, formas y demás cualidades en que se ofrece el mundo. Mirar es habitar el paisaje, mirar es habitar el mundo de la vida. Es descubrir en mi experienciar infinidad de planos de significación. En suma, percibir es habitar el mundo por la mirada.

Ahora se nos hace claro la se paración entre Husserl y Merleau-Ponty. Husserl necesita de un doble rendimiento de la conciencia trascendental para alcanzar el eidos ${ }^{5}$ del objeto percibido. Por una parte, la conciencia debe captar las sensaciones; para hacerlas claras debe exigirle a la conciencia alcanzar el plano de la reflexión, la cual permite la reducción de los datos de la vivencia a la conciencia. De esta forma, Husserl pretende tener la cosa misma del objeto, a través de su teoría de la graduación que conduce a la compenetración trascendental6. Por el

5 Heidegger desde su obra temprana Ontología hermenéutica de la facticidad emprende la tarea crítica contra una concepción tan estrecha del método fenomenológico heredero de la modernidad. “Desde un principio su tema es el ser-objeto, la objetividad de determinados objetos, y objeto para un pensar teórico indiferente, o el ser objeto material para determinadas ciencias que se ocupan con él, de la naturaleza, o de la cultura; y el mundo, pero no considerada desde el existir y las posibilidades del existir, sino siempre a través de las regiones de objetos; o también el añadido de otros rasgos no teoréticos. Lo que de ello resulta es que la ontología se cierra el acceso al ente que es decisivo para la problemática filosófica: el existir, desde el cual y para el cual es la filosofía" (Heidegger, 1999, p. 20).

6 La deficiencia de la teoría de la percepción también aplica para el plano de constitución intersubjetiva. En efecto, para Husserl el otro se da en primera instancia como objeto de percepción, es decir, se da al torrente de experiencia como objeto entre los objetos, cuerpo entre cuerpos, paradoja que, según Gadamer, Husserl trataría de explicar a través de su teoría de la graduación, que comporta dos fases: la primera es la percepción de lo otro con todas sus cualidades formales; y la segunda fase, cuando al objeto se le atribuye animación, lo cual Husserl denominó compenetración trascendental. Para Heidegger, esta teoría es limitada y reduce lo otro a mera representación teniendo como resultado que el otro no se perciba en su vitalidad, es decir, como un hecho caporal manifestado en la vitalidad del experienciar. Declara Gadamer: “Husserl insistió por lo menos en que el otro sólo puede estar dado en un principio como objeto de percepción y no en su vitalidad, no como un hecho corporal" (Gadamer, 2001, p. 21). 
contrario, Merleau-Ponty entiende el percibir como comprender sentido, la mirada como un habitar el horizonte de los objetos en donde el cuerpo se encuentra inserto. El redimiendo de la conciencia trascendental como garante de la reflexión ya no se hace necesario, pues la conciencia trascendental es encarnada, es carne, cogito encarnado.

Ya abordado el tema de la percepción, ahora es necesario indagar por el asunto de la temporalidad. El tiempo también debe ser interpretado como horizonte, en donde los éxtasis de la temporalidad se reúnen en el ahora, en la facticidad. El pasado determina el presente y proyecto mi futuro desde el pasado que se hace carne en mi presente. El tiempo se hace claro bajo la perspectiva del horizonte y los objetos también se ven atravesados por la temporalidad. Ejemplifiquemos. En las paredes de una casa, se conserva el tiempo transcurrido, se evidencia en el proceso de envejecimiento que se desvela en la pintura y las maderas que conforman su estructura. Los objetos tiene su tiempo, el horizonte en el cual se me dan los objetos se interrelacionan con el horizonte temporal:

Cada momento del tiempo toma a los demás como testigos, muestra, al producirse, cómo tal cosa tenía que acabar y en qué habrá parado tal cosa; cada presente hunde definitivamente un punto del tiempo que solicita el reconocimiento de los demás; el objeto se ve, pues, desde todos los tiempos igual a como se ve desde todas partes y, por el mismo medio, la estructura del horizonte (Merleau-Ponty, 1984, p. 89).

Finalmente, Merleau-Ponty cierra la sección del preámbulo recordando su objetivo central. El tratamiento que la ciencia ha dado al cuerpo como un objeto que desconoce, que el cuerpo-objeto es una de las fases de la constitución de la corporalidad, pero no la única ni la definitiva. Esto dibuja inmediatamente el objetivo que tratará de alcanzar en la sección I. Ni las concepciones mecanicistas sobre el cuerpo, ni la fisiología cartesiana, ni la psicología han logrado desvelar el vínculo entre cuerpo y mundo. De esta forma, su objetivo central es la fundamentación de una ontología de la corporalidad para que muestre, que lo manifestado en el cuerpo es el movimiento de la existencia, es la existencia, es el ser-del-mundo que no puede ser objetivado.

\section{Críticas al mecanicismo y a la fisiología}

Pero yo no estoy delante de mi cuerpo, estoy en mi cuerpo, o mejor, soy mi cuerpo. Ni sus variaciones ni su invariante pueden, luego, plantearse expresamente. Nosotros no contemplamos únicamente las relaciones de los segmentos de nuestro cuerpo y las correlaciones del cuerpo visual y del cuerpo táctil: somos nosotros mismos el que mantiene junto estos brazos y estas piernas, el que a la par, ve y toca.

Merleau-Ponty, 1984, p. 167

Iniciemos este apartado recordando el objetivo que Merleau-Ponty se propone en la sección I de la primera parte de la Fenomenología de la percepción titulada: El cuerpo como objeto y la fisiología mecanicista. El concepto de 'cuerpo' acuñado por la ciencia moderna entraña un problema fundamental: si el cuerpo se reduce a una unidad biológica, atravesada por procesos químicos y expuestos a las leyes físicas, ¿cómo explicar su relación con el espíritu? En otras palabras, ¿ cómo poder interpretar la relación entre el cuerpo como mera hyle y los procesos psíquicos que no pueden ser negados? Acaso nos enfrentamos a un dualismo entre cuerpo y alma imposible de ser solucionado. Y, de otra parte, si el sujeto sólo puede ser entendido a través de sus procesos psíquicos, ¿cómo explicar que el sujeto experiencia las afecciones en el cuerpo?

No sobra recordar que Merleau-Ponty conoce las consecuencias de las explicaciones que sobre el cuerpo ofreciera el racionalismo, en especial de corte cartesiano. En efecto, la modernidad se funda en el principio regulador propuesto por Descartes, en el cogito cartesiano, el cual deja suspendida la subjetividad al reducirla al acto de pensar; más aun, si preguntamos ¿qué es el yo de Descartes?, de inmediato podremos responder, siguiendo a Ricoeur7: "Es un yo

7 De manera concreta, la introducción, va desde el problema de la exaltación del cogito hasta el problema de la subjetividad herida 0 quebrada. 
sin cuerpo, sin espacio, sin tiempo, es nadie" (Ricoeur, 1996, p. 25)8.

Empero, aunque esta suspensión va a guiar las críticas más severas en torno a la subjetividad cartesiana, no podemos dejar de lado que este argumento no pueda considerarse como la cosa misma del error de Descartes. Quizá sea más preciso afirmar que su gran desacierto es el olvido del sujeto. En efecto, Descartes busca una certeza, la cual le permita afirmar que los juicios que elaboramos sobre el mundo son verdaderos y para ello somete a duda todo principio que le parezca sospechoso; pero luego de analizar todo juicio descubre que la única certeza que existe es la preeminencia del cogito, el cual se pone como principio y fin de todo conocimiento (parangón). Sin embargo, esta preeminencia gnoseológica y ontológica tendrá por resultado que la pregunta por el quién de la misma duda, se pierda. De esta manera, la subjetividad cartesiana se hunde a sí misma en su pretensión de certeza.

Descartes llegará incluso a prescindir del mundo, del espacio y el tiempo y, finalmente, del otro (plano intersubjetivo), que también desaparece en la fundamentación del sujeto trascendental que cae en el solipsismo más severo.

Pero, inmediatamente, después advertí que mientras quería pensar de ese modo que todo es falso, era absolutamente necesario que yo, que lo pensaba, fuera alguna cosa. Y observando que esta verdad: pienso, luego soy, era tan firme y tan segura que todas las más extravagantes suposiciones de los escépticos no eran capaces de socavarla, juzgué que podía admitirla como el primer principio de la filosofía que buscaba. [...] Conocí por ello que yo era una substancia cuya esencia o naturaleza no es sino pensar, y que, para existir, no necesita de lugar alguno ni depende de cosa alguna material. De manera que este yo, el alma por la cual soy, es enteramente distinta del cuerpo e incluso más fácil

8 Al respecto, Manuel Alejandro Prada afirma: "No obstante, podría preguntarse: ¿el qué de la duda es necesariamente alguien corporal, de carne y hueso, con un referente espacio-temporal?" Ricoeur responde negativamente: "Un yo sin anclaje es nadie". Narrarse a símismo: residuo moderno en la hermenéutica de Paul Ricoeur. En: Folios. Segunda época. 17, primer semestre del 2003, pp. 47-55. de conocer que él y, aunque el cuerpo no existiese, el alma no dejaría de ser todo lo que es (Descartes, 1993, pp. 46-47. AT, vol. 32- AT, vol. 33).

Es conocido que Descartes no podrá superar el solipsismo, el cual ha dejado el mundo suspendido y, también, la imposibilidad de pensar al sujeto como subjetividad a flor de piel que se constituye intersubjetivamente. Por el contrario, el cuerpo queda reducido a una cosa más, que puede ser explicado como un objeto mecánico y es aquí donde MerleauPonty encuentra la posibilidad de rechazar la teoría mecanicista sobre el cuerpo.

Lo primero que se le hace claro a Merleau-Ponty es que las explicaciones ofrecidas sobre el cuerpo han impedido alcanzar una comprensión total de lo que significa que somos cuerpos, porque el cogito cartesiano se encuentra en alguna parte y su lugar más próximo es la carne. Es por ello mismo que se ve obligado a hacer frente al mecanicismo y la fisiología moderna. Pero, ¿cuál es el error de la fisiología moderna?, separar el cuerpo de sus aspectos psicológicos, y en la medida que se incurre en este error, se es incapaz de explicar fenómenos como el del miembro fantasma o la anosognosia.

De esta forma, el filósofo francés se remite a la explicación que la fisiología moderna ofrece del cuerpo para poder evidenciar que esta separación no permite alcanzar una concepción del cuerpo como carne. Inicialmente Merleau-Ponty retoma el caso del excitante. Las excitaciones de un mismo sentido son distintas por el modo como espontáneamente se articulan las sensaciones primarias entre sí. Es gracias a esta organización lo que permite que "un excitante" dé espacio a una sensación táctil. En seguida el sujeto creerá que "el excitante", se mueve y dibujará un círculo sobre su piel. Finalmente, ya no sentirá nada. Una excitación no se puede percibir cuando afecta a un órgano sensorial que no está en la línea de aquélla. La función del organismo en la percepción de los estímulos es interpretar cierta manifestación de la excitación.

Empero, frente a lo anterior, podría asegurarse que esta experiencia del cuerpo es una representación que se halla engranada en una serie de procesos físicos y fisiológicos que son los únicos con 
derecho a aceptarse al momento de interpretar el cuerpo biológico. Para hacer frente a este último argumento, Merleau-Ponty se vale del ejemplo de la amputación. Si un sujeto que haya padecido amputación, una estimulación reemplaza a la de la pierna perdida en el trayecto que va del muñón al cerebro, el sujeto sentirá una pierna fantasma, pues el alma se encuentra correlacionada con el cerebro. MerleauPonty quiere hacer anotar que la explicación de la fisiología no puede desatender los antecedentes psicológicos: una emoción, una circunstancia que recuerda a las emociones de la herida hacen surgir un miembro fantasma en los sujetos que no lo tenían. El fenómeno del "miembro fantasma", se hace explícito de la mano del fenómeno de anosognosia ${ }^{9}$ que hace imperativa una explicación psicológica. Es así como Merleau-Ponty hace notar, cómo los factores psíquicos y fisiológicos se correlacionan:

Si el 'miembro fantasma' depende de condiciones fisiológicas y, en cuanto tal, es el efecto de una causalidad en tercera persona, no se entiende cómo, por otro parte, pueda depender de la historia personal del enfermo, sus recuerdos, sus emociones o voluntades [...] Una teoría mixta, que aceptase las dos series de condiciones pueden ser válidas como enunciado de los hechos conocidos, pero serán profundamente oscuras. [...] Sólo podría ser una mezcla de ambos, si encontrásemos la manera de articular el uno sobre el otro, [es decir], lo psíquico y lo fisiológico (Merleau-Pony, 1984, p. 96).

De esta forma, Merleau-Ponty logra evidenciar que el problema del "miembro fantasma" no surge de una simple causalidad pretendidamente objetiva. De otro lado, tampoco el problema puede ser reducido a factores psicológicos. Solamente si hallamos correlación entre los factores fisiológicos y psicológicos lo para-sí y lo en-sí, y se posibilita un encuentro entre ellos se descubre que cuerpo y alma jamás han estado separados, más aún, siempre han estado en intimidad. De otro lado, en ocasiones para referirse al trauma del miembro fantasma, se afirma

9 ¿Pero qué es la 'anosognosia'?: es la ignorancia de la existencia de una enfermedad. que es una represión o una contención orgánica; estos conceptos describen la afección producida por el trauma y el rechazo de la mutilación.

Sin embargo, lo importante de la referencia a estos términos es que nos invitan a la constitución de una mirada holística sobre el cuerpo por medio de la cual la relación de lo psíquico y lo fisiológico resulta posible. Ejemplifiquemos. El amputado siente su pierna, como cada uno de los que nos encontramos en este salón de estudios, y puede experienciar la existencia de ese ser querido que por el momento se encuentra ausente. Lo que Merleau-Ponty quiere explicitar es que la experiencia del brazo amputado como presente, o de un brazo enfermo como ausente, no corresponden a la del yo pienso cartesiano. Este fenómeno rebasa las explicaciones psicológicas y fisiológicas, y es posible que pueda ser comprendido gracias a una nueva perspectiva: la del ser-del-mundo.

Se da, pues, una cierta consistencia de nuestro mundo, relativamente independiente de los estímulos, que prohibe tratar el ser-del-mundo como una suma de reflejos - una cierta energía de la pulsación de la existencia, relativamente independiente de nuestros pensamientos voluntarios que prohibe tratarlo como un acto de conciencia-. Es por ser una visión preobjetiva que el ser-delmundo puede distinguirse de todo proceso en tercera persona (Merleau-Ponty, 1984, p. 99).

El ser-del-mundo es la existencia encarnada, el cogito encarnado, el 'cuerpo' es el medio en que la existencia se correlaciona con el mundo. Esta correlación no es de carácter tético, más aún, ni siquiera puede ser objeto de ninguna ciencia porque la relación que vincula cuerpo y mundo antecede todo plano de explicación teórica. El cogito moderno por fin ha hallado su cosa misma: la existencia. El ser-delmundo es un cuerpo que se instala en el mundo de la vida no mediante el acto de pensar, sino gracias a la percepción, a la mirada, al movimiento del cuerpo que lo hacen un habitante que se reconoce en la finitud y en la especialidad. Ahora el cuerpo no es objeto, ahora el cuerpo es el sentido descubierto del mundo. Ahora puedo afirmar que soy carne, que experiencia el mundo. ㄴ. 


\section{Bibliografía}

Descartes, R. (1993). Discurso del método. Barcelona: Altaya.

Gadamer, H. G. (1993). "Superación del planteamiento epistemológico en la investigación fenomenológica”. En: Verdad y método I. Salamanca: Sígueme.

Gadamer, H. G. (2001). "Subjetividad e intersubjetividad, sujeto y persona (1975)”. En: El giro hermenéutico. Madrid: Cátedra.

Heidegger, M. (1999). “Ontología hermenéutica de la facticidad". Madrid: Alianza.

Husserl, E. (1986). “Meditación quinta. En que la esfera trascendental del ser se revela como intersubjetividad monadológica”. En: Meditaciones cartesianas. México, Fondo de cultura económica.

Husserl, E. (1949). Ideas relativas a una fenomenología pura y una filosofía trascendental. México: Fondo de cultura económica.

Husserl, E. (1994). Problemas fundamentales de la fenomenología. Madrid: Alianza.
Husserl, E. (1998). "Artículo fenomenológica de la enciclopedia Británica”. En: Invitación a la fenomenología. Barcelona: Paidós.

Prada, M. (2003). "Narrarse a sí mismo: residuo moderno en la hermenéutica de Paul Ricoeur” En: Folios. Bogotá: Universidad Pedagógica Nacional.

Patocka, J. (2000). El movimiento de la existencia. Barcelona: Encuentro.

Ponty, M. (1984). Fenomenología de la percepción. Barcelona: Planeta Agostini.

Ponty, M. (2000). Sentido y sin sentido. Barcelona: Península.

Ricoeur, Pl. (1996). Sí mismo como otro. México: Siglo XXI.

Rosales, A. (2000). “Conocimiento, vida y cuerpo”. En: Fenomenología en América Latina. Bogotá: Universidad de San Buenaventura. 
